【国際セッション】

\title{
EARLY DEVELOPMENTAL ENVIRONMENT AND OLYMPIC SUCCESS: HISTORICAL ANALYSIS OF AN AUSTRALIAN SPORTING "HOTSPOT"
}

\author{
O’Neill, K., Cotton, W. and O'Connor, D. \\ The University of Sydney, Sydney, Australia
}

\section{Introduction}

Inspired by the 'birthplace effect' phenomenon (Côté et al., 2006), this study aimed to identify an Australian sporting "hotspot" and gain understanding of factors underpinning a proportionately high number of Australian summer Olympians experiencing their early developmental environment within the area.

\section{Methods}

A mixed-methods approach was utilised to identify the "hotspot" through collecting biographical data on all known ( $\mathrm{n}=2160)$ Australian summer Olympians 1984-2012, followed by undertaking a case study analysis to examine the "hotspot" within the context of Bronfenbrenner's (1979, 1994) 'Ecological Systems Theory' and 'Bioecological Model'.

\section{Results}

Alongside the archival collection of demographic and climate data, Olympians' $(n=11)$ and community stakeholders $(n=31)$ views regarding the "hotspot's" occurrence and its perceived influence on athletic development were triangulated through semi-structured interviews. Although not predominantly attributable to one variable, it was evident a confluence of planned and fortuitous factors had unintentionally created a "hotspot" of Australian summer Olympians in Perth, Western Australia.

\section{Discussion}

Despite several demographic, geographic, historical, individual and environmental factors being unique to the "hotspot", those pertaining to family, access to facilities, the junior sports environment and individual psychological characteristics are potentially transferable to other athlete development environments in Australia and overseas. Ultimately, Olympians' considered these factors to most strongly influence their athletic development.

\section{References}

Bronfenbrenner U. (1979). The ecology of human development: experiments by nature and design. Cambridge, MA: Harvard University Press.

Bronfenbrenner U, Ceci SJ. (1994). Nature-nurture reconceptualized in developmental perspective: a bioecological model. Psychological Review, 101(4), 568-586. doi: 10.1037/0033-295X.101.4.568

Côté J, Macdonald DJ, Baker J, Abernethy B. (2006). When "where" is more important than "when": birthplace and birthdate effects on the achievement of sporting expertise. Journal of Sports Sciences, 24(10), 1065-1073. doi: 10.1080/02640410500432490 